\title{
Aplikasi Passing Grade Program Studi Perguruan Tinggi Negeri di Indonesia dengan Menerapkan Algoritma Zhu Takaoka
}

\author{
Ahmadin Sahri \\ Program Studi Teknik Informatika, STMIK Budi Darma, Medan, Indonesia \\ Email: sahriahmadin@gmail.com
}

\begin{abstract}
Abstrak-Passing Grade sering dijadikan sebagai patokan akan kesempatan atau pertimbangan akan kelulusan ke perguruan tinggi. Dan dari passing grade itu kita juga bisa melihat tingkat kelulusan ke program studi perguruan tinggi negeri tersebut, karena jika passing gradenya semakin tinggi maka tingkat kelulusan program studi semakin rendah dan sebaliknya, jika passing gradenya semakin rendah maka akan semakin tinggi tingkat kelulusan ke program studi tersebut. Masalah yang terjadi adalah pengetahuan tentang passing gradenya, karena setiap siswa/i tidak mengetahui tentang passing grade setiap jurusan di perguruan tinggi negeri di Indonesia. Yang akan membuat siswa/i akan merasa bimbang dan ragu untuk memilih jurusan dan perguruan tinggi yang mempunyai peluang dan kemampuan siswa/i untuk meraih jurusan dan perguruan tinggi yang siswa/i yang diinginkan. Berdasarkan permasalah di atas akan diselesaikan menggunakan algoritma string maching, yaitu algoritma zhu takaoka. Yang akan melakukan pencocokan karakter atau kriteria dan akan memunculkan output yang mempunyai kesamaaan atau pencocokan. Di samping itu penelitian ini berbasis android, Yang akan memungkinkan penggunaannya yang lebih cepat, mudah dan efisien.
\end{abstract}

Kata Kunci: Passing Grade, Perguruan Tinggi Negeri, Algoritma Zhu Takaoka

\begin{abstract}
Passing Grades are often used as a benchmark for opportunities or considerations of graduation to college. And from the passing grade, we can also see the level of graduation to the state higher education study program, because if the passing grade is higher then the graduation level of the study program is lower and vice versa, if the passing grade is getting lower then the higher the level of graduation to the study program. The problem that occurs is the knowledge of the passing grade, because every student does not know about the passing grade of each major at a state tertiary institution in Indonesia. Which will make students / $\mathrm{i}$ will be hesitant and hesitant to choose majors and colleges that have the opportunity and ability of students to achieve majors and colleges that students want. Based on the above problems will be solved using the string maching algorithm, the zhu takaoka algorithm. Which will do the character or criteria matching and will bring up output that has the same or matching. In addition this research is based on Android, which will enable its use to be faster, easier and efficient.
\end{abstract}

Keywords: Passing Grade, State University, Zhu Takaoka Algorithm

\section{PENDAHULUAN}

Seperti yang sudah diketahui bahwa semua siswa menginginkan untuk kuliah di sebuah perguruan tinggi negeri yang di sukainya, dan tentunya setiap Perguruan Tinggi Negeri mempunyai passing gradenya sendiri yang terbagi dalam bebagai jurusan-jurusan di dalam Perguruan Tinggi Negeri tersebut.

Pada dasarnya passing grade sering dijadikan sebagai patokan akan kesempatan atau pertimbangan kelulusan ke Perguruan Tinggi Negeri di Indonesia. Berdasarkan passing grade itu kita juga bisa melihat tingkat kesempatan lulus ke program studi Perguruan Tinggi Negeri tersebut, karena jika passing gradenya semakin tinggi maka tingkat kesempatan lulus program studi semakin rendah dan sebaliknya, jika passing gradenya semakin rendah maka akan semakin tinggi tingkat kesempatan lulus ke program studi tersebut [1].

Masalah yang terjadi adalah pengetahuan siswa/i tentang passing gradenya, karena setiap siswa/i tidak mengetahui tentang passing grade setiap jurusan di Perguruan Tinggi Negeri di Indonesia, Sehingga tidak mempunyai pertimbangan dalam memilih jurusan Perguruan Tinggi Negeri di Indonesia.

Algoritma string matching adalah algoritma pencocokan yang sering digunakan untuk mencari atau mencocokkan data yang mempunyai kemiripan, oleh karena itu penulis berpikir akan membuat aplikasi tentang passing grade di setiap Perguruan Tinggi Negeri di Indonesia yang akan menggunakan algoritma string maching, yaitu algoritma zhu takaoka [2]. Yang akan melakukan pencocokan karakter atau kriteria dan akan memunculkan output yang mempunyai kesamaaan atau pencocokan.

\section{METODE PENELITIAN}

\subsection{Passing Grade}

Seperti yang sudah diketahui bahwa passing grade adalah suatu nilai yang memprediksi dan dapat membantu siswa/i SMA yang baru lulus. Passing grade tersebut sering dibuat sebagai acuan atau patokan untuk memilih perguruan tinggi yang diinginkan, dari pernyataan di atas dapat kita simpulkan bahwa passing grade adalah suatu penentu atau pemandu siswa/i SMA dalam hal menentukan nilai kelulusan dan keberhasilan dalam menggapai perguruan tinggi yang diinginkan.

\subsection{Algoritma Zhu-Takaoka}


Algoritma Zhu-Takaoka merupakan algoritma hasil modifikasi dari algoritma pencocokan string algoritma BoyerMoore yang diciptakan oleh Boyer R.S dan Moore J.S pada tahun 1977. Algoritma Zhu-Takaoka kemudian dikembangkan oleh Zhu Rui Feng dan Tadao Takaoka yang dipublikasikan pada tahun 1986. Algoritma ZhuTakaoka memiliki ciri-ciri yang sama dengan algoritma Boyer-Moore dalam proses pencarian string, yaitu adanya preprocessing, right-to-left scan, bad character rule, dan good suffixes rule. Walaupun memiliki persamaan dalam proses pencarian string, dua algoritma ini tetap memiliki perbedaan, yaitu terletak pada tahap penentuan bad character rule. Dimana pada algoritma Boyer-Moore, bad character hanya terdiri array satu dimensi, sedangkan pada algoritma Zhu-Takaoka dimodifikasi menjadi array dua dimensi.

Pada tahap preprocessing algoritma Zhu-Takaoka membangun tabel bad character 2 dimensi karena algoritma tersebut menghitung untuk pasangan karakter. Kompleksitas waktu dari tahap preprocessing adalah $\mathrm{O}(\mathrm{m}+\mathrm{o} 2)$ dan kompleksitas waktu fase pencarian adalah $\mathrm{O}(\mathrm{mn})$. Proses inti pencarian algoritma Zhu-Takaoka yaitu dilakukan dengan teknik right-to-left scan rule. Teknik ini membandingkan pattern yang dicari dengan sumber text dimulai dari kanan ke kiri [2].

\section{ANALISA DAN PEMBAHASAN}

Masalah pada penelitian ini adalah tingkat keefektifannya kurang dalam proses pencarian passing grade Perguruan Tinggi Negeri di Indonesia. Menyebabkan siswa/i lulusan SMA kesulitan untuk menentukan Perguruan Tinggi Negeri yang mereka inginkan karena kurangnya pengetahuan tentang passing grade. Aplikasi passing grade yang akan dirancang untuk mengatasi masalah tersebut dan dibangun berbasis android dengan menerapkan algoritma Zhu Takaoka pada pencarian passing grade pada Perguruan Tinggi Negeri di Indonesia.

Pada proses ini akan dilakukan perancangan aplikasi menggunakan perangkat lunak IDE Eclipse Editor kode program dan android SDK (Software development kit) yang akan dimanfaatkan untuk pengembangan aplikasi dalam Bahasa pemrograman java dan juga Android Development Tools (ADT). Pengkodingan hasil dari perancangan aplikasi yang dilakukan pada smartphone dan laptop yang didukung oleh sistem android.

Algoritma Zhu Takaoka pada aplikasi passing grade ini dicontohkan pada salah satu Perguruan Tinggi Negeri di Indonesia yang berupa tabel, Tabel tersebut terdiri dari nama Perguruan Tinggi Negeri, Nama jurusan dan passing grade disetiap jurusan yang beragam dengan nilai passing gradenya yang diambil dari https://sbmptn.ac.id. Data nama jurusan di salah satu Perguruan Tinggi Negeri di Indonesia dan masing-masing passing grade dapat dilihat pada tabel 1 .

Tabel 1. Nama Salah Satu Perguruan tinggi Negeri dan Passing Grade.

\begin{tabular}{lll}
\hline Nama Perguruan Tinggi Negeri & Nama Jurusan & Passing Grade \\
\hline Universitas Islam Negeri Sunan Kalijaga Yogyakart & Fisika & $24,84 \%$ \\
& Biologi & $24,20 \%$ \\
& Teknik Informatika & $32,78 \%$ \\
& Pendidikan Agama Islam (PAI) & $23,60 \%$ \\
Universitas Negeri Medan (UNIMED) & Teknik Industri & $31,92 \%$ \\
& Biologi & $27.6 \%$ \\
& Fisika & $28.0 \%$ \\
Universitas Negeri Jakarta (UNJ) & Ilmu Keolahragaan & $24.2 \%$ \\
& Kimia & $26.8 \%$ \\
& Teknik Elektro & $30,8 \%$ \\
& Fisika & $30,63 \%$ \\
& Pendidikan Agama Islam (PAI) & $23.00 \%$ \\
& Biologi & $33,56 \%$ \\
& Teknik Elektro & $30,58 \%$ \\
& Ekonomi & $32,50 \%$ \\
Universitas Sumatera Utara (USU) & Teknik Elektro & $41,1 \%$ \\
& Teknik Sipil & $40,52 \%$ \\
& Fisika & $30,2 \%$ \\
& Biologi & $31,3 \%$ \\
& Kimia & $30,2 \%$ \\
& Teknik Sipil & $30,5 \%$ \\
& Teknik Elektro & $30,8 \%$ \\
& Pendidikan Agama Islam (PAI) & $32.8 \%$ \\
& Biologi & $32,5 \%$ \\
& Fisika & $34,9 \%$ \\
\hline
\end{tabular}




\subsection{Penerapan Algoritma Zhu-Takaoka}

Penerapan algoritma Zhu-Takaoka pada pencarian pattern dan tahap pertama yang dilakukan algoritma Zhu Takaoka ialah preprocessing yang membuat 2 buah tabel pergeseran ztBc (Zhu Takaoka Bad Character) dan bmGs (Boyer Moore Good Suffix). Pencarian pattern akan menentukan terciptanya tabel, maka jika patternnya berubah akan berubah juga tabelnya. Proses preprocessing pada pencarian pattern "PAI" pada teks "Jurusan PAI" dapat dilihat di bawah ini.

Pattern $=$ PAI

Teks $=$ Jurusan PAI

Tabel 2. Zhu Takaoka Bad Character

\begin{tabular}{cccc}
\hline $\mathrm{ZtBc}$ & $\mathrm{P}$ & $\mathrm{A}$ & $*$ \\
\hline $\mathrm{P}$ & 1 & 2 & 3 \\
$\mathrm{I}$ & 2 & 2 & 3 \\
$*$ & 2 & 2 & 3 \\
\hline
\end{tabular}

Tabel 3. Boyer Moore Good Suffix

\begin{tabular}{cccc}
\hline I & 0 & 1 & 2 \\
\hline X[i] & P & A & I \\
Suffix & 1 & 0 & 3 \\
BmGs & 1 & 2 & 3 \\
\hline
\end{tabular}

Tahap pencarian pattern "PAI" pada teks "jurusan PAI" menggunakan algoritma Zhu Takaoka adalah sebagai berikut :

Pencarian pada teks langkah 1:

\begin{tabular}{|l|l|l|l|l|l|l|l|l|l|l|l|}
\hline Window & P & A & & & & & & & & & \\
\hline Teks & J & U & R & U & S & A & N & - & P & A & I \\
\hline Pattern & P & A & I & & & & & & & & \\
\hline I & 0 & 1 & 2 & & & & & & & & \\
\hline
\end{tabular}

$z t B c[P][A]=2$

$b m G s[i]=b m G s[1]=2$

Pattern PAI tidak ditemukan pada teks sehingga $z t B c$ yang terdapat pada window untuk mencocokkan teks, kemudian pergeseran dilakukan ke kanan dengan penentuannya diambil dari nilai $b m G s[\mathrm{i}]=b m G s[1]=2$. Melakukan pergeseran sebanyak 2

Pencarian pada teks langkah 2:

\begin{tabular}{|c|c|c|c|c|c|c|c|c|c|c|c|}
\hline Window & & & P & A & & & & & & & \\
\hline Teks & J & U & R & U & S & A & N & - & P & A & I \\
\hline Pattern & & & P & A & I & & & & & & \\
\hline I & & & 0 & 1 & 2 & & & & & & \\
\hline
\end{tabular}

$z \boldsymbol{t B c}[P][A]=2$

bmGs[i] $=b m G s[1]=2$

Pattern PAI tidak ditemukan pada teks sehingga $z t B c$ yang terdapat pada window untuk mencocokkan teks, kemudian pergeseran dilakukan ke kanan dengan penentuannya diambil dari nilai $b m G s[\mathrm{i}]=b m G s[1]=2$. Melakukan pergeseran sebanyak 2

Pencarian pada teks langkah 3:

\begin{tabular}{|c|c|c|c|c|c|c|c|c|c|c|c|}
\hline Window & & & & & P & A & & & & & \\
\hline Teks & J & U & R & U & S & A & N & - & P & A & I \\
\hline Pattern & & & & & P & A & I & & & & \\
\hline I & & & & & 0 & 1 & 2 & & & & \\
\hline
\end{tabular}

$z t B c[P][A]=2$

bmGs $[i]=b m G s[0]=1$

Pattern PAI tidak ditemukan pada teks sehingga $z t B c$ yang terdapat pada window untuk mencocokkan teks, kemudian pergeseran dilakukan ke kanan dengan penentuannya diambil dari nilai $b m G s[i]=b m G s[0]=1$.

Melakukan pergeseran sebanyak 1

Pencarian pada teks langkah 4:

\begin{tabular}{|c|c|c|c|c|c|c|c|c|c|c|c|}
\hline Window & & & & & & & & & & & \\
\hline Teks & J & U & R & U & S & A & N & - & P & A & I \\
\hline
\end{tabular}




\begin{tabular}{|c|l|l|l|l|l|l|l|l|l|l|l|}
\hline Pattern & & & & & & & & & P & A & I \\
\hline I & & & & & & & & & 0 & 1 & 2 \\
\hline
\end{tabular}

Proses pergeseran berhenti, karena semua pattern sudah ditemukan pada teks dan selanjutnya akan menampilkan detail dan passing grade pada teks view. Selanjutnya akan muncul hasil pencarian yang dapat dilihat pada tabel di bawah ini:

Tabel 4. Hasil Pencarian

\begin{tabular}{ccc}
\hline Nama Perguruan Tinggi Negeri & Nama Jurusan & Passing Grade \\
\hline UIN Sunan Kalijaga Yogyakarta & PAI & $23,60 \%$ \\
UNJ & PAI & $23.00 \%$ \\
UPI & PAI & $32.8 \%$ \\
\hline
\end{tabular}

\subsection{Implementasi}

Implementasi sistem program ini mencakup spesifikasi kebutuhan perangkat keras (hardware) dan spesifikasi perangkat lunak (software). Berikut ini perincian dari tampilan output dari perangkat lunak, Dimana yang telah tertera pada gambar yang menunjukkan tampilan menu utama.

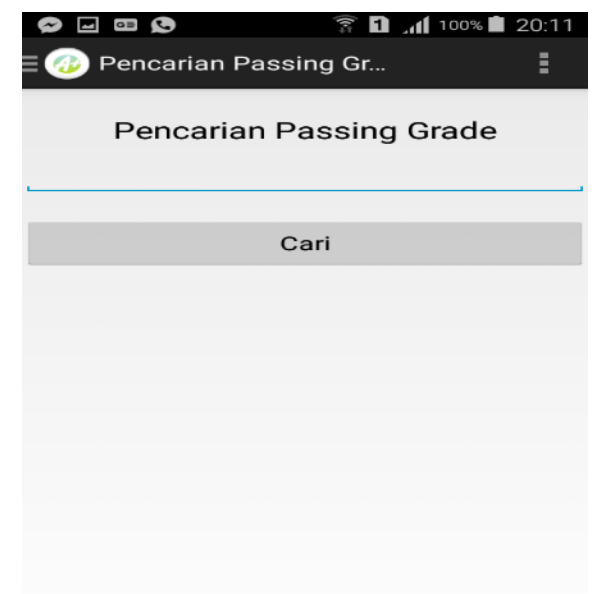

Gambar 1. Tampilan Menu Utama

Tampilan ini berisi pencarian Passing Grade yang berhubungan dengan Perguruan Tinggi Negeri di Indonesia, dimana pengguna dapat melakukan pencarian Passing Grade dengan cara memasukkan teks menu ke dalam textbox yang tersedia di aplikasi.

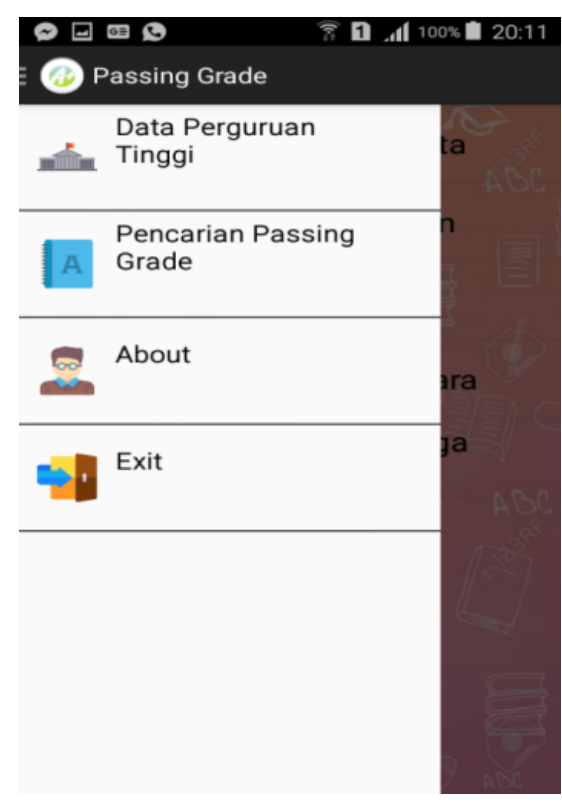

Gambar 2. Tampilan Pencarian 
Setelah di klik menu cari maka hasil pencarian akan muncul tampilan nama Perguruan Tinggi Negeri dan Passing Grade yang tertera pada tampilan hasil pencarian, di bawah ini berikut tampilan hasil pencarian Passing Grade.

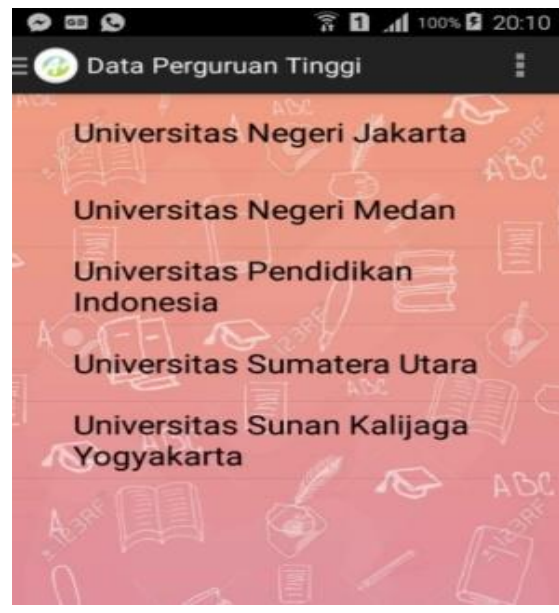

Gambar 3. Tampilan Hasil Pencarian

Tampilan ini berisi tentang informasi tentang Passing Grade dimana pengguna bisa melihat tentang keterangan Passing Grade.

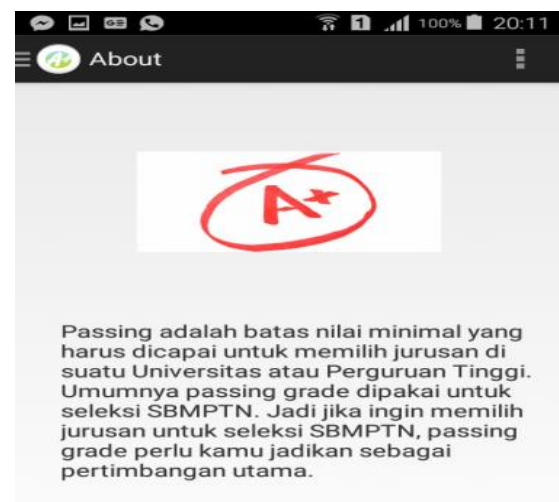

Gambar 4. Tampilan About Passing Grade.

\section{KESIMPULAN}

Berdasarkan pembahasan sebelumnya serta pengujian yang sudah dilakukan, maka bisa diambil beberapa kesimpulan yaitu :

1. Hasil dari penelitian ini adalah sebuah aplikasi Passing Grade yang dikembangkan dengan eclipse juno.

2. Dengan adanya aplikasi Passing Grade dapat memberi kemudahan pengguna dalam pencarian Passing Grade Perguruan Tinggi Negeri di Indonesia.

3. Lebih mengenal manfaat algoritma zhu takaoka pada penggunaan aplikasi passing Grade berbasis android.

\section{REFERENCES}

[1] Alawiah Enok Tuti, "Rancangan Aplikasi Smart City Berbasis Mobile Untuk Meningkatkan Kulitas Layanan Publik Studi Kasus Pemkot Bogor," 2017.

[2] B. E. S Jailamm Igaph, Mesran, “Aplikasi Mobile Pencarian Kata Pada Arti Ayat Al-qur'an Berbasis Android Menggunakan Algoritma String Matching," 2016.

[3] D. Saragih Ambon, "Perancangan Aplikasi E-Library Menggunakan Bahasa Pemrograman PHP Pada Universitas Methodist Indonesia," 2015.

[4] Kadir Abdul, Pengenalan Algoritma Pendekatan Secara Visual Dan Interaktif Menggunakan Raptor. Yogyakarta: CV Andi Offset, 2013.

[5] D. Togatorop Gutman, Erlansari Aan, "Implementasi Algoritma Zhutakaoka Pada Aplikasi Kamus Istilah Musik Berbasis Android," 2017.

[6] D. Supriyono Heru, Saputra Ardhiyatama Nur, "Rancang Bangun Aplikasi Pembelajaran Hadis Untuk Perangkat Mobile Berbasis 
JSON Volume 1, Nomor 2, Januari 2020

e-ISSN 2685-998X

DOI 10.30865/json.v1i2.1938

Android," 2014

[7] Supardi Yuniar, Belajar Coding Android Bagi Pemula. Jakarta: PT Elex Media Komputindo, 2015.

[8] Sulistyorini Prastuti, "Pemodelan Visual dengan Menggunakan UMLdan Rational Rose," 2009.

[9] A. E. M. Satyaputra Alfa, Beginning android Programming with ADT Bundle. Jakarta: PT Elex Media Komputindo, 2014.

[10] EMS Tim, Pemrograman Android Dalam Sehari. Jakarta: PT Elex Media Komputindo, 2015. 